\title{
Education: The key to development
}

\author{
P. T. M. Marope ${ }^{1}$
}

Published online: 2 November 2019

(C) UNESCO IBE 2019

In 2015, the Advisor to the Director-General of UNESCO, Hans d'Orville (2015, p. 91), made the point in the build-up to the adoption of the Sustainable Development Goals (SDGs) that "the need for an inclusive, sustainable concept has never been so critical. Sustainable development with its three pillars-economic, social, and environmental-has come to be the central plank of the post-2015 sustainable development agenda... Arguably, at the heart of this agenda lies the notion of a new humanism".

Although the contributors to this issue inhabit a vast spectrum of cultures, represent different horizons of thought, and belong to different generations, they commonly seek to frame the idea of development in ways that allow us to think more constructively and less instrumentally about the place of education within it. Included in this "general" issue are articles that bear, directly and explicitly, on the complexity of the links between development and education, with important topics ranging from international organizations and conflict, to inclusive education, sustainability, and community participation.

The issue opens with a powerful Viewpoint authored by Crain Soudien, a leading voice in comparative education, Chief Executive Officer of the Human Sciences Research Council, and formerly a Deputy Vice-Chancellor at the University of Cape Town. Professor Soudien critiques the ways in which the ideas of development and education are held together and highlights the significance of the new humanist movement for development. He argues for a restatement of the idea of development that draws on the consensus about its meaning emerging out of the SDGs and which also brings to bear the discussion concerning new humanism.

Crain Soudien's Viewpoint is followed by a throughout analysis of the relationship between international organizations, educational development, and conflict, seen through a (world) cultural perspective. Conflict perspectives have been crucial in explaining national educational expansion and change. With the intensifying globalization of education in the more recent period, researchers and policy makers have conceptualized educational

P. T. M. Marope

ibe.prospects@unesco.org

1 UNESCO International Bureau of Education Geneva, Geneva, Switzerland 
conflicts beyond the nation-state. They now understand these conflicts as involving a growing number of international organizations, including intergovernmental organizations, international nongovernmental organizations, development banks, and bilateral development agencies. The article authored by Mike Zapp, researcher at the Institute of Education and Society, Université du Luxembourg, focuses on these international organizations as new players, whose interest in education has received considerable momentum since the Education for All initiative in the early 1990s. Zapp reveals a covert cultural conflict between international organizations' universalistic goals of educational equality and progress and the practices of "traditional culture" that international organizations have observed in the field. International organizations perceive such culture as impeding the former's educational development goals. Analysis further identifies international organizations' decoupling of their formal commitment to cultural diversity and local context from their actual practice of standardizing policy. Such decoupling reflects tensions inherent in contemporary world culture and provides a novel perspective on international organizations' role in educational globalization.

Christopher Johnstone, Sheryl Lazarus, Predrag Lazetic, and Gordana Nikolic examine an important challenge to achieving inclusive education in the Central Eastern European region: funding. Europeanization, influence of United Nations agencies, and shifts away from Soviet models of education have led to new policy aspirations for the inclusion of children with special education needs (SEN) in Central and Eastern Europe. At the same time, policies in many countries often lack the infrastructure or internal mechanisms required for successful implementation (such as funding, professional capacity, and public will). Through simulations based on data that the authors collected in the Republic of Serbia, the authors examine approaches for funding children with SEN in inclusive classrooms, without losing the supports provided to them in segregated settings. Their findings illustrate the possible approaches to adequate costing of inclusive education policies and potentially serve as a methodological reference beyond specific national contexts.

The link between gender and primary-school dropout in Sudan is the topic of Kathleen Fincham's article. Within the Sudanese context, education retention and completion are major challenges that have not seriously and sufficiently addressed. In order to understand in more depth how and why children drop out of primary school in Sudan, six empirical studies were planned as part of an EU-funded national programme focused on primary education and retention in the five states with the lowest basic education completion rates: Blue Nile, Gedaref, Kassala, South Kordofan, and Red Sea. Fincham's article discusses the second study (looking at the factors affecting the education and retention of girls in Red Sea State) with the aim of providing a deeper and more comprehensive understanding and analysis of the challenges that girls, in particular, face in accessing schooling, staying in school, and completing the primary cycle (grades 1-8). Specifically, the article provides insights into the processes of dropout and indicators of risk factors that one can use to predict dropout for girls.

In light of Australian policy and curriculum initiatives aimed to prioritize Education for Sustainability (EfS) practices, Melissa Barnes, Deborah Moore, and Sylvia Almeida discuss a study that evaluated a smart-meter program introduced by a local government of an Australian state/territory. The program aimed to provide teachers and students from 86 primary and secondary schools access to data on energy, gas, and water consumption through a website that digitally recorded schools' consumption in real time. While the Australian curriculum supposedly prioritizes EfS as a cross-curriculum aim, the results from this small study suggest that EfS is neither a priority nor cross-curricular. The authors conclude that alternative approaches are needed, to make sustainability a priority in the 
Australian curriculum and to ensure that all the schools support sustainability and the resources associated with it. For this systems approach to work in initiating change toward a more cohesive EfS, each stakeholder needs to be aware of her or his "small part" in connecting within a larger system, rather than feeling inconsequential in the bigger picture of global sustainability.

The Free Primary Education policy in Kenya created a dichotomy between the widespread notion that the government should be responsible for everything and the reality that the government had stopped recruiting teachers. By focusing on the "client power" of parents and communities, Mikiko Nishimura investigates the current state of the accountability system for school governance in public schools in the Maasai community in Loitokitok District, Kajiado County. A case study of eight schools in the Masai community reveals that a sense of "working together" and a substantial degree of client power are present in various school initiatives. Elements that enhance client power include information sharing, collaboration and coordination with stakeholders, critical-thinking ability, respect and trust, and other unique efforts. The study also indicates the limitations of the dichotomous lens of "service provider" and "client" and questions the instrumental approach to community participation in school management.

\section{References}

D’Orville, H. (2015). New humanism and sustainable development. Cadmus, 2(5). http://cadmusjournal. org/node/503.

Publisher's Note Springer Nature remains neutral with regard to jurisdictional claims in published maps and institutional affiliations. 